\title{
Experimental Research of Mineral Admixtures on the Uniaxial Tensile Capacity of PVA Reinforced Cementitious Composite
}

\author{
Qing $\mathrm{Su}^{1, \mathrm{a}}$, Zhixiong Tao ${ }^{2, \mathrm{~b}}$
}

\author{
1. Whchang University of Technology, Wuhan, 430223 \\ 2. CITIC General of Architectural Design and Research Co.Ltd, 430010 \\ a1094076970@qq.com, b110934440@qq.comemail
}

Key words: Mineral admixture; PVA; Uniaxial tension

Abstract. Uniaxial tension capacity was tested on the two groups of PVA reinforced cement composite with fly ash and silica fume. The results indicate the specimen mixed with Grade I fly ash has higher tensile strength and better strain hardening ability. Compared with the specimen without silca fume, the initial crack strength, ultimate tensile strength fo the one with $100 \mathrm{~kg} / \mathrm{m}^{3}$ silica fume has been increased $97 \%$ and $30 \%$, respectively. The ultimate tensile strain decreased $6.7 \%$.

\section{Introduction}

Poor durability of cemetitious material has been always caused by fracture under low tensile strength. Lots of research indicated that PVA fiber (PVA) with high strength and high modulus can enhance the tensile properties of the cementitous materials, the fiber on the propagation of the microcracks block and inhibition, cement base material behavious in strain hardening and seam cracking characteristics. The fiber reinforced cementitous composites with high toughness, excellent crack harmless dispersion ability and high frost resistance has been widely used in the damaged repariment and structural durability protection.

The mineral admixtures such as fly ash and silica fume has been used to improve the hydration of cement, increase the compactness, improve strength of cement paste, enhance permeability resistance ${ }^{[1]}$. However, the varieties and dosage is the key factors influencing its application. In this papar, the uniaxial tensile test has been carried out to investigate the effect of variety and dosage of mineral admixtures on the tension property of cmentitious composite reinforced by PVA fiber.

\section{Experiment}

Material and Composition

The material has been used in unaixal test includes, P.O42.5 cement, fly ash choose I grade and II grade, REC15 PVA fiber, silica fume with class of 920, quartz sand with maximum diameter of 0.3 $\mathrm{mm}$ and superplasticizer. The mixture composition is shown in Table 1.

Table 1 The Mixture Compostion $\left[\mathrm{kg} / \mathrm{m}^{3}\right]$

\begin{tabular}{cccccccc}
\hline Group & Silica fume & Fly ash & Cement & Sand & Water & PVA & Superplasticizer \\
\hline CC-I & 0 & 650 & 550 & 550 & 301 & 26 & 4.4 \\
\hline CC- II & 0 & 650 & 550 & 550 & 301 & 26 & 4.4 \\
\hline CC-50 & 50 & 600 & 550 & 550 & 301 & 26 & 5.1 \\
\hline CC-100 & 100 & 550 & 550 & 550 & 301 & 26 & 5.9 \\
\hline
\end{tabular}

Experimental Schedule

The dumbbell specimen has been prepared for experiment, which designed reference to the Japanese recommended Recommendations for Design and Construction of High Performance fiber Reinforced Cement Composites with Multiple Fine Cracks (HPFRCC), shown in Fig.1. The cement and sand has been mixed $2 \sim 4$ min, then water and superplasicizer has been added and mixed $2 \mathrm{~min}$ 
again, when the slurry has good liquidity and adhesiveness, the PVA fiber added. The specimen mould after $24 \mathrm{~h}$ and cured $14 \mathrm{~d}$ in standard curing room.

\section{Results and Discussion}

In order to study the effect of mineral admixtures on the uniaxial tensile properties of PVA reinforced cementitious materials (hereinafter PVA-CC), seven groups specimens has been prepared and cured until stipulated date for test. According to the unaxial test, the stress-strain curve drawed, and conclued the parameters the early crack strength $\left(f_{t}\right)$, the initial crack strain $\left(\varepsilon_{0}\right)$, tensile modulus of elasticity $(E)$, ultimate tensile strength $\left(f_{\mathrm{tu}}\right)$ and ultimate tensile strain $\left(\varepsilon_{\mathrm{tu}}\right)$.

According to above parameters, the discussion has been developed as following.

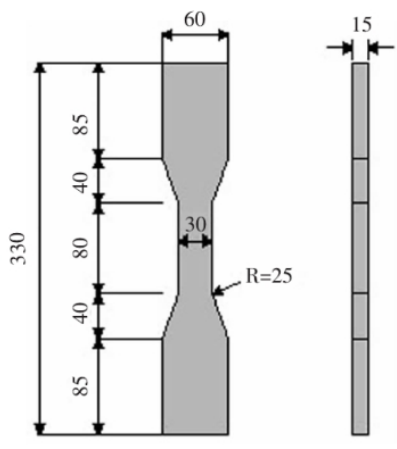

Fig.1 dumbbell specimen

The influence of fly ash

The specimen with different varieties of fly ash has been carried tensile test after $14 \mathrm{~d}$ curing. The crack distribution in tensile process is shown in Fig. 2 and stress-strain curve drawed in Fig.3. The tensile performance parameters of specimens listed in Table 2.

Comparing Fig.2 and Fig.3, it can be seen that under the effect of axial tension, the cracks of group CC-I is more and fine, distributing evenly over the observation area. The specimen of group CC- II only appeared few crack in the observation area, and ultimately be pulled apart along the main fracture.

On the basis of investigation of lots of experimental phenomena and analysis, the results can be concluede is that load vibration corresponds to emergence of new crack, which means the number of load vibration nearly equal to the number of cracks. Furthermore, the more load vibration, the greater of crack width ${ }^{[2]}$. Therefore, the develop and tendency of cracks can be seen from $\sigma-\varepsilon$ curve for the specimen under uniaxial tension ${ }^{[3]}$.From Fig.2 and Fig.3, which can be seen that the stress vibration in the strain hardening is small, and the wave number is more, the group CC-I exhibit obvious strain hardening and more cracking, and strain hardening period of group CC-II is extremely short, less vibration and stress. The Fig. 3 coincides well with the test observation of crack development.

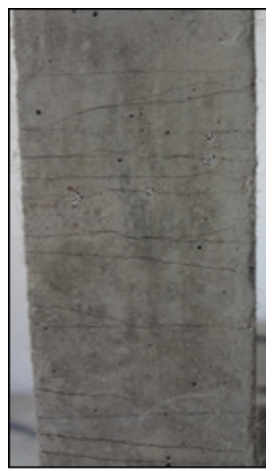

(a) crack distribution

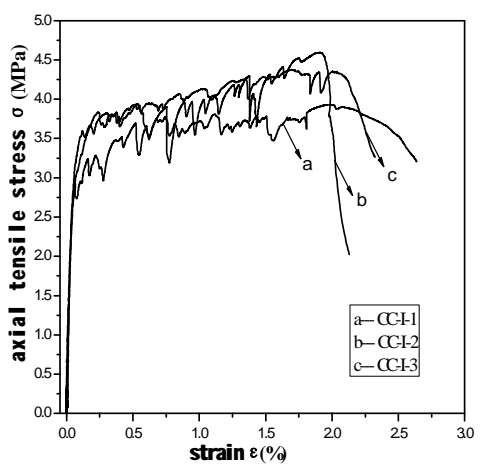

(b) $\sigma-\varepsilon$ curve

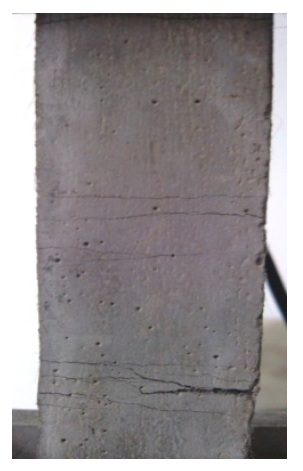

(a) crack distribution

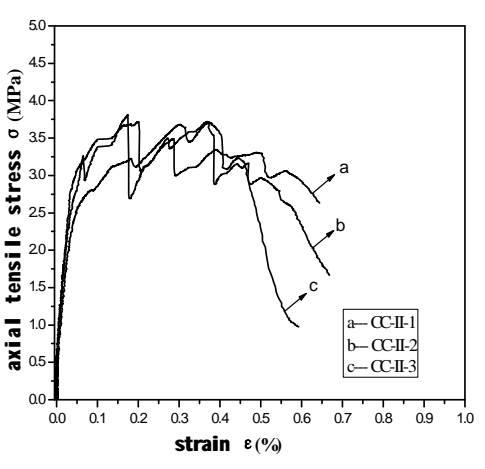

(b) $\sigma-\varepsilon$ curve

Fig. 2 The unaxila tension of group CC-I

Fig.3 The unaxila tension of group CC-II

By analyzing test data, the initial crack strength $\left(f_{\mathrm{t}}\right)$ of group CC-I is increased $15.7 \%$ than CC-II, ultimate strength $\left(f_{\mathrm{tu}}\right)$ increased $37.3 \%$ and ultimate strain $\left(\varepsilon_{\mathrm{tu}}\right)$ increased nearly 3 times. From the perspective of microstructural analysis, the spherical particles content of grade I fly ash is higher than that of grade II, the glass sphere has good dispersion and lubrication performance, and the higher the content of glass sphere, the better of ball bearings effect of fly ash, and the more prominent of strain hardening effect to PVA- $\mathrm{CC}^{[4]}$. 
Table 2 The tensile parameters of specimen with fly ash

\begin{tabular}{c|c|c|c|c|c}
\hline Group & $f_{\mathrm{t}}[\mathrm{MPa}]$ & $\varepsilon_{0}\left[10^{-2}\right]$ & $\mathrm{E}[\mathrm{Gpa}]$ & $f_{\mathrm{tu}}[\mathrm{MPa}]$ & $\varepsilon_{\mathrm{tu}}\left[10^{-2}\right]$ \\
\hline CC-I & 3.46 & 0.017 & 19.97 & 4.27 & 2.09 \\
\hline CC-II & 2.99 & 0.019 & 15.75 & 3.11 & 0.51 \\
\hline
\end{tabular}

The influence of silica fume

In order to study the effect of varitey and dosage of fly ash, silica fume on the properties of PVA - CC under uniaxial tension, three groups of CC-I, CC-50 and CC-100 after 7d curing were selected to carry out experiment. The stress-strain curve drawed in Fig. 4 and performance parameters listed in Table 3.

Table 3 The tensile parameters of PVA-CC

\begin{tabular}{c|c|c|c|c|c}
\hline Group & $f_{\mathrm{t}}[\mathrm{MPa}]$ & $\varepsilon_{0}\left[10^{-2}\right]$ & $\mathrm{E}[\mathrm{Gpa}]$ & $f_{\mathrm{tu}}[\mathrm{MPa}]$ & $\varepsilon_{\mathrm{tu}}\left[10^{-2}\right]$ \\
\hline CC-I & 2.75 & 0.26 & 10.58 & 4.12 & 5.5 \\
\hline CC-50 & 3.08 & 0.24 & 12.83 & 4.43 & 5.24 \\
\hline CC-100 & 5.42 & 0.18 & 30.11 & 5.37 & 5.13 \\
\hline
\end{tabular}

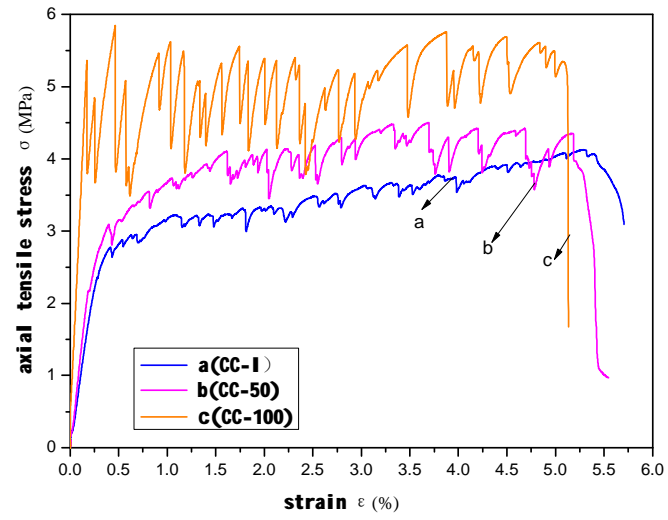

Fig.4 The unaxila tension of group PVA-CC

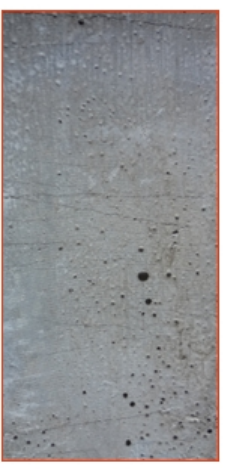

(a)CC-I

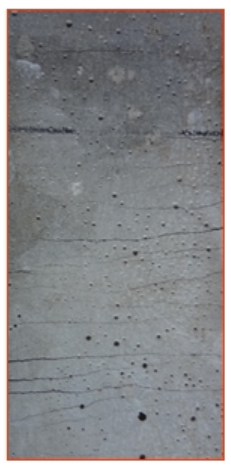

(b)CC-50

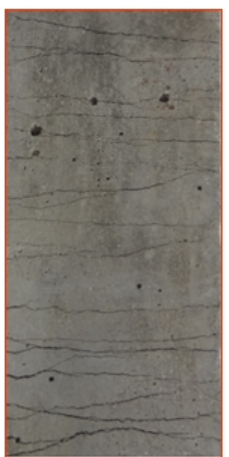

(c)CC-100

Fig.5 The crack distribution of PVA-CC

Under uniaxial tension, all three groups specimen with different dosage of silica fume showed obvious strain hardening and more cracking (as shown in Fig.5), ultimate $\operatorname{strain}\left(\varepsilon_{\mathrm{tu}}\right)$ has been greater than 5\%.The parameter in Table 3 shows the early crack stress $\left(f_{t}\right)$ of three groups are $2.75 \mathrm{MPa}, 3.08$ $\mathrm{MPa}$ and 3.08 MPa respectively. The early crack stress $\left(f_{\mathrm{t}}\right)$ of group CC-100 with $100 \mathrm{~kg} / \mathrm{m}^{3}$ silica fume has been increased nearly 1 times than CC-I with only fly ash, improved $76 \%$ than group CC-50.The limit stress $\left(f_{\text {tu }}\right)$ and elastic modulus $(E)$ also improved obviously. The silica fume has excellent role of filling pores and accelerating hydration. With the increaseing of silica fume, the stress-strain curve vibrates obviously, which means the crack width is larger at that time.Combined with Fig.5, the specimens of CC-100 behaviors in more cracks evenly distributed throughout the observation area. All above indicates that silica fume in cement paste can help to reduce the water loss in the process of vibrating, improve the early strength of the specimens, and reduce initial injury in moulding.

The reason of that silica fume hardening might be that the silica fume can improve the strength of cement matrix, and strengthen the bond between matrix and fiber interface. With the stress increasing, some fibers is pulled, the force measured is limit tensile stress of fiber itself instead of cohesive force between fiber and matrix. Fiber fractured and energy released, which result in the crack width increase $^{[5-6]}$. In the experiment of this paper, crack develop and extend faster in early stage, then the number of crack has a linear growth with the increasing of strain, further crack number grow significantly slower, and width expand quickly until the main crack failure. 


\section{Conclusions}

Based the strain-stress curve of PVA reinforced specimen mixed with fly ash and silica under uniaxial tensile test, some conclusions have been drawn as following:

(1) The strain-stress curve of specimen with fly ash of grade I and grade II both show strength and strain hardening. The improving effect of grade I fly ash is more obvious than that of grade II.Class II fly ash and water demand is bigger, only rely on increasing dosage of water reducing agent almost short of strain hardening cement base composite materials tensile property requirements.

(2) Being active and filling effect, silica fume can significantly improve the tensile ability of PVACC. With the dosage $100 \mathrm{~kg} / \mathrm{m}^{3}$ of silica fume, the initial crack strength of PVA-CC reach $5.42 \mathrm{MPa}$, increased by $97 \%$ than that only fly ash, ultimate strength increased by $30 \%$, and ultimate tensile strain decreased $6.7 \%$.

\section{Acknowledgements}

This work was financially supported by the Hubei province Science and Technology Project.

\section{References}

[1] Wang Hong, Chen Wei-tian, Chen Chang-li: Experimental Research on the Effect of Silica Fume on the Strength of HSC.Concrete Vol. 7 (2011), p. 74-76

[2] Li Hedong: Experimental Research on Ultra High Toughness Cementitious Composites[D]. Dalian University of Technology.2008

[3] Wang Liljiu, Ai Hongmei, WangZan: Study of cementitious coefficient of fly ash. Journal of Dalian University of Technology. Vol. 42 (2002), p. 724-727

[4] Rao Fanfeng. Experimental Research on Influence of Fly Ash on Flexural Properties of Ultra High Toughness Cementitious ComPosite[D]. Dalian University of Technology.2008

[5] Cai Xiangrong. Clem: The basic mechanical Performance and Strain Hardening Process

Theoretical Analysis of Ultra High Toughness Cementitious Composite[D]. Dalian University of Technology.2010

[6] Zhou Qiaoqing, Cai Chuanrong, He Yanbin: Microstructure and strength of Reactive PowderConcrete. J.Chin.Electr.Miscr.Soc. Vol.22(2003),p. 594-595 